\title{
High Protein Pre-Term Infant Formula: Effect on Nutrient Balance, Metabolic Status and Growth
}

\author{
RICHARD COOKE, NICK EMBLETON, JACQUES RIGO, ANNELISE CARRIE, FERDINAND HASCHKE, AND \\ EKHARD ZIEGLER
}

\begin{abstract}
The Royal Victoria Infirmary [R.C., N.E.], Newcastle NE1 4LP, United Kingdom; Service Universitaire do Neonatologie [J.R.], CHR de la Citadelle, 4000 Liege, Belgium; Nestec Ltd [A.C., F.H.], CH-19300 Vevey, Switzerland; Department of Pediatrics [E.Z.],

University of Iowa Hospitals, IA 52240
\end{abstract}

\begin{abstract}
Several lines of evidence suggest that formula with protein content of $3.0 \mathrm{~g} / 100 \mathrm{kcal}$ does not fully meet the protein needs of very-low-birth weight infants. Our purpose was to compare nitrogen balance, metabolic status and growth in infants fed a standard (3.0 g/100 kcal; RegPro) and high (3.6 g/100 kcal; HiPro) protein infant formula. Infants were fed both formulas, each formula for one week in balanced cross-over design. Metabolic status was monitored throughout. Nutrient balance and plasma amino acids were determined at the end of each week. Data were analysed using a linear mixed model. Eighteen infants were studied. Nine infants received the RegPro and nine received HiPro formula first. Nitrogen intake, absorption and retention were greater with the HiPro formula. None of the infants developed uremia or metabolic acidosis but retinol-binding-protein and weight gain were greater with the HiPro formula. Increased protein accretion paralleled by better weight gain without evidence of metabolic stress indicates that a formula with a protein content of $3.6 \mathrm{~g} / 100 \mathrm{kcal}$ better meets protein needs in these rapidly-growing infants. Further studies are needed to determine whether these short-term outcomes will be translated into long-term benefits. (Pediatr Res 59: 265-270, 2006)
\end{abstract}

$\mathrm{T}$ here is compelling evidence that premature infants frequently do not receive protein intakes that meet their needs $(1,2)$. In the case of formula-fed infants, one critical reason is that pre-term formulas contain too little protein. The protein needs of premature infants are reasonably well established based on the factorial method and experimental data. By one estimate, protein requirements are $4.0 \mathrm{~g} / \mathrm{kg} / \mathrm{d}$ for infants weighing less than $1200 \mathrm{~g}$, decreasing to $3.9 \mathrm{~g} / \mathrm{kg} / \mathrm{d}$ for infants weighing 1200-1500 g (3). Expressed per unit of energy, the requirements for protein are $3.8 \mathrm{~g} / 100 \mathrm{kcal}$ for infants weighing 500-700 g, decreasing gradually to 3.1 $\mathrm{g} / 100 \mathrm{kcal}$ for infants weighing 1200-1500 g (3).

A formula that provides $3.0 \mathrm{~g} / 100 \mathrm{kcal}$, therefore, cannot provide an adequate intake of protein. If needs of these infants are to be met, a formula must provide more than $3.0 \mathrm{~g} / 100$ $\mathrm{kcal}$. We, therefore, hypothesized that a formula with a protein concentration of $3.6 \mathrm{~g} / 100 \mathrm{kcal}$ would lead to greater nitrogen

Received January 24, 2005; accepted August 25, 2005.

Correspondence: Richard Cooke, M.D., Newborn Center, Suite 201, Department of Pediatrics, University of Tennessee Center for the Health Sciences, 853 Jefferson Ave, Memphis 38163; e-mail: rcooke@utmem.edu

DOI: 10.1203/01.pdr.0000196376.99101.34 retention and greater short term weight gain than a formula with a protein concentration of $3.0 \mathrm{~g} / 100 \mathrm{kcal}$. The present study was designed to test this hypothesis.

\section{METHODS AND PROCEDURES}

Study design. The study design was based on a previous study in pre-term infants and is outlined in Table 1 (4). It comprised of 2 one-week comparison periods during which each formula was fed. It was conducted in a double blind fashion, with the sequence of formula feeding randomly determined and balanced. Immediately before the first study formula was fed, baseline (anthropometric, metabolic) determinations were made. After a minimum equilibration period of $72 \mathrm{~h}$, anthropometric and metabolic determinations were repeated and the first metabolic balance study was begun. At the end of the first balance period the anthropometric and metabolic determinations were again obtained. The second study formula was then fed and the process repeated. When the second balance was completed, final anthropometric and metabolic determinations were again obtained and the study ended.

Studies were performed at the Royal Victoria Infirmary, Newcastle upon Tyne, UK and at Service Universitaire de Neonatologie Liege, Liege, Belgium. The study was approved by the Ethics Committees at each study site. Written informed consent was obtained from the infant's parent(s), who were given a written outline of the study.

Each of the two metabolic balance periods lasted $48 \mathrm{~h}$. Carmine red was used to mark the beginning and end of the stool collection period. During the balance periods formula intake was $135 \mathrm{~mL} / \mathrm{kg} / \mathrm{d}$ or more. Blood was obtained immediately before the first study formula was started and again at the beginning and end of each balance period. Weight was measured at the beginning of the study and at the beginning and end of each balance period.

Sample size. Nitrogen retention was the primary outcome. Assuming a difference of $30 \mathrm{mg} / \mathrm{kg} / \mathrm{d}$, a SD of $20 \mathrm{mg} / \mathrm{kg} / \mathrm{d}$ for balances in the same infant, a power of 0.80 and a $p<0.05,10$ infants were required to detect such a difference. Allowing for center-to-center variation, 18 infants were deemed necessary to complete the study.

Subjects. Pre-term infants with birth weights $\leq 1500 \mathrm{~g}$ and gestational ages $\leq 32$ wk were eligible if they were clinically stable and received feeding volumes of at least $130 \mathrm{~mL} / \mathrm{kg} / \mathrm{d}$ and had not received postnatal steroids or diuretics. Infants requiring oxygen were considered eligible only if oxygen therapy was discontinued by the time the first balance study was due.

Study formulas. The composition of the formulas is presented in Table 2. The formulas differed primarily with respect to their concentration of protein $(3.0 \mathrm{v} 3.6 \mathrm{~g} / 100 \mathrm{kcal})$. In both formulas, protein was provided by fully hydrolyzed bovine whey protein. The hydrolyzed protein was chosen because it has been associated with better feeding tolerance, an important consideration in these infants (5). There were small differences in the total amount of carbohydrate and in the proportion provided by lactose. There were also some differences in sodium ( $1.8 \mathrm{v} 2.8 \mathrm{mmol})$, chloride $(1.8 \mathrm{v} 2.7 \mathrm{mmol})$ and vitamin A $(350 \mathrm{v} 500 \mathrm{IU} / 100 \mathrm{kcal})$. The amino acid content of the formulas is presented in Table 3. The higher protein concentration of Formula HiPro was reflected in proportionately higher amino acid concentrations.

Procedures. During the first balance study, infants were generally fed by continuous nasogastric infusion and volume of intake was maintained at

Abbreviations: PAA, plasma amino acids; RBP, retinol-binding protein; TEAA, total essential amino acids; TNEAA, total non-essential amino acids 
Table 1. Study design

\begin{tabular}{lllllr}
\hline & \multicolumn{3}{c}{ Begin } & \multicolumn{2}{c}{ End } \\
\cline { 2 - 6 } & Equilibration & Balance 1 & Equilibration & Balance 2 \\
\hline Day & 1 & 4 & 7 & $11-14$ \\
Anthropometry & $X$ & $X$ & $X$ & $X$ & X \\
Biochemistry* & $X$ & $X$ & $X$ & $X$ & X \\
\hline
\end{tabular}

* BUN and acid-base status on days 1, 4, 7, 11, 14. Plasma amino-acids, retinol-binding-protein and transferrin on days 7 and 14 .

$135-150 \mathrm{~mL} / \mathrm{kg} / \mathrm{d}$. During the second balance, some infants were fed by continuous infusion and intake maintained at $135-150 \mathrm{~mL} / \mathrm{kg} / \mathrm{d}$. Others were fed to appetite when intake exceeded $150 \mathrm{~mL} / \mathrm{kg} / \mathrm{d}$.

During the balance collections, care of the study infant was provided by nurses responsible only for the study infant. These nurses were specially trained in the care of the pre-term infant and the performance of nutrient balance collections. The overall care of the infants was under the direction of the responsible physician. All regular nursing procedures were performed as clinically indicated.

The frequency of blood sampling was also based on our previous study (4). Blood urea, blood $\mathrm{pH}$, and base excess were determined in all blood samples to monitor for the development of uremia or metabolic acidosis. Neither occurred and values obtained at the end of each balance period were analysed for differences between the HiPro and RegPro formulas. Total serum proteins, albumin, retinol binding protein (RBP), serum transferrin and plasma amino acids (PAA) were measured at the end of each balance collection.

Venous blood sampling was performed in the morning at the end of a feeding cycle (continuous feeds) or immediately before a feed (bolus feeds). Blood gas analysis was performed immediately. Heparinised plasma was separated immediately and used for urea, total protein and albumin determination or stored at $-30^{\circ} \mathrm{C}$ for later RBP, transferrin and PAA determination.

Methods. Nutrient balance collections were performed as previously described (6). Bottles of formula were weighed before and after each feed; differences in weights were calculated to determine formula intake. Spillage was collected on preweighed diapers placed around the infant; differences in weight between the clean and 'soiled' diapers indicated losses which were subtracted from measured intake.

Urine and stool (girls) and stool (boys) were collected in Pyrex dishes placed underneath the infants. Urine in boys was collected via a urine collection bag. Urine, feces and formula were analyzed for nutrient content at the Samuel J. Fomon Infant Nutrition Unit, University of Iowa, as described previously (7) and Service Universitaire de Neonatologie Liege, Belgium. Briefly, nitrogen was determined by micro-Kjeldahl digestion followed by a

Table 2. Composition of study formulas (/100 kcal)*

\begin{tabular}{lcc}
\hline \multicolumn{1}{c}{ Formula } & RegPro & HiPro \\
\hline Caloric density (kcal/100 ml) & 80 & 80 \\
Protein (g) & $3.0(2.96)^{* *}$ & $3.6(3.58)^{* *}$ \\
Protein quality & hydrolyzed whey & protein \\
Fat $(\mathrm{g})$ & 5.2 & 5.2 \\
MCT $(\%)$ & 25 & 30 \\
Palmitic Acid (\%) & 10 & 10 \\
Arachidonic acid (\%) & 0.2 & 0.2 \\
Docosahexanoic Acid (\%) & 0.3 & 0.3 \\
Carbohydrates (g) & 10.5 & 9.9 \\
Lactose/Maltodextrin & $40 / 60$ & $20 / 80$ \\
Minerals & & \\
Sodium (mg) & 55 & 64 \\
Potassium (mg) & 120 & 136 \\
Chloride (mg) & 85 & 95 \\
Calcium (mg) & $131(143)$ & $131(142)$ \\
Phosphorus (mg) & $75(81)$ & $75(79)$ \\
Magnesium (mg) & $8.0(8.2)$ & $9.0(9.2)$ \\
Copper (mg) & $(0.16)$ & $(0.13)$ \\
Zinc (mg) & $1.2(1.55)$ & $1.2(1.40)$ \\
Vitamin B6 (mg) & 0.075 & 0.075 \\
\hline
\end{tabular}

* Provided by manufacturer.

** Values in parentheses determined at the SJ Fomon Infant Nutrition Unit and used for balance calculations.
Table 3. Amino acid and ammonium content of study formulas $(\mathrm{mg} / 100 \mathrm{kcal})^{*}$

\begin{tabular}{lcc}
\hline \multicolumn{1}{c}{ Formula } & RegPro & HiPro \\
\hline Asparagine & 372 & 471 \\
Threonine & 166 & 220 \\
Serine & 140 & 176 \\
Glutamic Acid & 527 & 646 \\
Proline & 144 & 182 \\
Glycine & 69 & 87 \\
Alanine & 158 & 198 \\
Cystine & 94 & 115 \\
Valine & 174 & 218 \\
Methionine & 72 & 91 \\
Isoleucine & 169 & 212 \\
Leucine & 401 & 505 \\
Tyrptophan & 77 & 95 \\
Tyrosine & 112 & 139 \\
Phenylalanine & 123 & 152 \\
Lysine & 308 & 386 \\
Ammonia & 50 & 67 \\
Histidine & 112 & 139 \\
Arginine & 114 & 141 \\
\hline
\end{tabular}

* Provided by manufacturer.

modified micro-diffusion analysis (8). Formula and feces were ashed at $525^{\circ}$ overnight and ashes dissolved in dilute hydrochloric acid. Calcium, magnesium, copper and zinc content of ashes and urine was determined by atomic absorption spectrophotometry (Perkin-Elmer A Analyst Model 100, Norwalk, CT 06859). Phosphorus was determined by the phosphomolybdate method described by Leloir and Cardini (9). Fat in feces was determined by a modification of the method of Van de Kamer et al. (10).

Volume of intake was calculated by dividing differences in weight by the specific gravity of the formula. Nutrient intake was calculated from the volume fed and content of the formula. Stool excretion was calculated from the weight and content of the stool, urine excretion from the volume and content of the urine. Absorption was calculated by subtracting fecal excretion from from intake, retention by subtracting urinary excretion from absorption.

Anthropometry was performed as previously described (6). Weight gain, expressed in $\mathrm{g} / \mathrm{d}$, was calculated from the difference in weights determined at the beginning and end of each study period, $7 \mathrm{~d}$ in all but three infants. In one infant, the study period was $6 \mathrm{~d}$. In the other two infants, the study period was $13 \mathrm{~d}$ because the balance collection was delayed due to technical difficulties. No differences were detected between the main study group and these three infants. Weight gain is also expressed in fractional terms $(\mathrm{g} / \mathrm{kg} / \mathrm{d})$, calculated by dividing weight gain $(\mathrm{g} / \mathrm{d})$ by the average weight for the study period.

Acid-base status and serum urea, total protein and albumin were analysed using routine laboratory methods. Transferrin was measured by immunoturbidimetry using the Tina-quant Transferrin Kit (Roche $\mathrm{N}^{\circ} 1931$ 628, Switzerland) (11). RBP was measured by immunoturbidimetry using a rabbit anti-human retinol-binding protein (12) with N Protein Standard SL (human) used as the calibrator (Dade Behring, Germany). Determinations were made using a BM/Hitachi 917 Analyzer (Roche, Switzerland). Plasma amino acids were determined as described by Bachmann \& Haschke-Becher (13).

Data were analyzed on an intention to treat basis using a linear mixed model to test for differences due to treatment corrected for period (fixed effect) and infant (random effect). The effect of sex on weight gain was determined by $t$-test. Analyses were performed using SAS Software (version 8.0), and results were considered significant at $p<0.05$.

\section{RESULTS}

Results are presented as mean \pm 1 SD. Eighteen infants ( girls $=9$, boys $=9$ ) were studied to completion, 16 in Newcastle and 2 in Liege. Birthweight and gestational age were $1226 \pm 204 \mathrm{~g}$ and $29.5 \pm 1.5 \mathrm{w}$. Infants were enrolled at $22 \pm 9 \mathrm{~d}$ of age, weighing $1471 \pm 225 \mathrm{~g}$. None of the infants received supplemental oxygen or medications during the study.

Nine infants were fed the RegPro and nine infants were fed the HiPro formula first. Subject characteristics are presented 
by study sequence in Table 4 . Birth weight and gestational age were less in infants fed the RegPro formula first $(p<0.05)$. These infants were also older when the first and second balances were performed. However, no differences were noted in corrected age or body weight between the sequences when the balances were performed.

Thirty-six balances were performed, two in each infant. Nitrogen absorption and retention were a linear function of intake $(p<0.001 ;$ Fig. 1$)$. The paired nitrogen results are presented in Fig. 2. Nitrogen absorption and retention were quite consistent for all but one infant. A summary of the results is presented in Table 5. Nitrogen intake, absorption and retention were greater with the HiPro formula $(p<0.001)$. Protein intakes (nitrogen $\times 6.25$ ) averaged 4.6 and $3.8 \mathrm{~g} / \mathrm{kg} / \mathrm{d}$ in infants fed the HiPro and RegPro formulas, respectively. No differences were detected in \% absorption or retention between the formulas. No differences were detected in nitrogen accretion between the sexes.

The remaining balance results are also presented in Table 6 . Fat intake was similar but fecal excretion was less and absorption was greater with the HiPro formula $(p<0.05)$. No significant differences were detected in calcium or phosphorus intakes, absorption and retention between the formulas. Although infants consumed more magnesium and less zinc no differences were detected in magnesium or zinc absorption or retention between the formulas. Copper intake and absorption were somewhat greater with the RegPro formula $(p<0.05)$.

None of the infants developed uremia (blood urea $\geq 7.0$ mmol) during the study. Blood urea was a linear function of nitrogen intake $\left(\mathrm{y}=-3.2+0.01 \mathrm{x}, \mathrm{r}^{2}=0.41, p<0.0001\right.$; Fig. 3) and absorption $\left(\mathrm{y}=-2.6+0.01 \mathrm{x}, \mathrm{r}^{2}=0.50, p<\right.$ 0.0001 ; Fig. 3) and was greater with the HiPro formula (3.5 \pm $1.3>2.1 \pm 0.8 \mathrm{mmol}, p<0.001)$. None of the infants developed a metabolic acidosis (base deficit $\geq-8.0$ ) (14). No relationship was detected between nitrogen intake and base deficit (Fig. 3) and no differences were noted in base excess $(1.6 \pm 1.5 \mathrm{v} 1.1 \pm 2.1 \mathrm{mM})$ between the formulas.

No differences were detected in total serum protein (44 \pm $3 \mathrm{v} 45 \pm 3 \mathrm{~g} / \mathrm{L})$, albumin $(31 \pm 3$ v $31 \pm 3 \mathrm{~g} / \mathrm{L})$ or transferrin $(20 \pm 3$ v $21 \pm 4 \mu \mathrm{M})$ concentrations. However, RBP

Table 4. Subject characteristics of study sequences (mean \pm 1 $S D, n=9 /$ sequence)

\begin{tabular}{lcc}
\hline \multicolumn{1}{c}{ Sequence } & $3.0-3.6 \mathrm{~g} / 100 \mathrm{kcal}$ & $3.6-3.0 \mathrm{~g} / 100 \mathrm{kcal}$ \\
\hline Birthweight (g) & $1152 \pm 195$ & $1300 \pm 194^{*}$ \\
Gestation (w) & $29 \pm 1.2$ & $30 \pm 1.5^{*}$ \\
Males:females & $5: 4$ & $4: 5$ \\
Enrollment & $1472 \pm 262$ & $1470 \pm 197$ \\
$\quad$ Weight & $26 \pm 8.5$ & $18 \pm 8^{*}$ \\
$\quad$ Postnatal age (d) & $32.7 \pm 0.7$ & 32.8 \\
$\quad$ Postconceptional age (w) & & \\
First balance & $1630 \pm 285$ & $1677 \pm 208$ \\
$\quad$ Weight & $32 \pm 8.2$ & $24 \pm 7.5^{*}$ \\
$\quad$ Postnatal age (d) & $33.6 \pm 0.9$ & $33.6 \pm 0.9$ \\
$\quad$ Postconceptional age (w) & & \\
Second balance & $1855 \pm 304$ & $1901 \pm 231$ \\
$\quad$ Weight & $39 \pm 8.3$ & $32 \pm 6^{*}$ \\
$\quad$ Postnatal age (d) & $34.5 \pm 0.8$ & $34.8 \pm 1.0$ \\
$\quad$ Postconceptional age (w) & &
\end{tabular}

* Differences significant at $p<0.05$
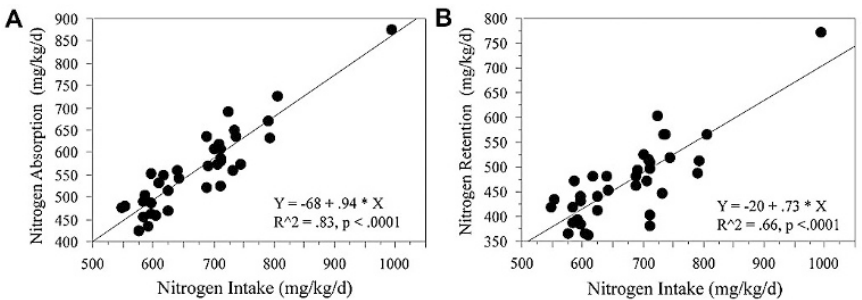

Figure 1. Relationship between nitrogen intake and nitrogen absorption and retention ( $n=36$ balances). Nitrogen absorption $(A)$ and retention $(B)$ were linearly related to nitrogen intake $(p<0.0001)$.

concentrations were greater with the HiPro formula (12.4 \pm $3.3>11.0 \pm 2.6 \mathrm{mg} / \mathrm{L} ; p<0.05)$, perhaps reflecting differences in vitamin A content between the formulas.

The paired weight gain data are presented in Fig. 4. Weight gain was remarkably consistent for all but one infant girl where it decreased from $48 \mathrm{~g} / \mathrm{d}$ (RegPro) to $31 \mathrm{~g} / \mathrm{d}$ (HiPro). The reason for this is not clear because nitrogen intake $(596 \mathrm{v}$ $688 \mathrm{mg}$ ), absorption (552 v $637 \mathrm{mg}$ ) and retention (441 v 483 $\mathrm{mg} / \mathrm{kg} / \mathrm{d}$ ) were less with the RegPro formula. Overall, weight gain was greater with the HiPro than the RegPro formula (35 $\pm 9>27 \pm 6 \mathrm{~g} / \mathrm{d} ; p<0.005$ ), an effect that tended to more marked in boys $(42 \pm 13>27 \pm 8 \mathrm{~g} / \mathrm{d})$ than girls $(34 \pm 9$ $>29 \pm 9 \mathrm{~g} / \mathrm{d}$ ); mean difference in gain between the sexes $=$ $10 \pm 16 ; p=0.07)$. Expressed in fractional terms, weight gain also differed between the formulas $(23.1 \pm 7>16.7 \pm 6$ $\mathrm{g} / \mathrm{kg} / \mathrm{d}$ for the HiPro and RegPro formulas).

The main PAA results are presented in Table 5 and compared with umbilical cord blood reference values (15). Total essential amino acids (sum of lysine, valine, phenylalanine, methionine, tryptophan, threonine, histidine, leucine, isoleucine) were greater in infants fed the HiPro formula $(p<0.05)$ but were less than the cord reference value. Concentrations of valine $(p<0.001)$ and lysine $(p<0.01)$ concentrations were significantly higher with HiPro but were still less than cord reference values. No differences were detected in plasma threonine between the formulas, but concentrations were somewhat greater than the cord reference.

Total nonessential amino-acids levels (sum of alanine, arginine, asparigine, citrulline, cysteine, glutamate, glutamine, glycine, ornithine, proline, serine, taurine, tyrosine) were greater with the HiPro formula $(p=0.01)$ but were still less than cord values. Increased asparagine, glutamine, proline, citrulline, tyrosine, and ornithine levels $(p<0.05)$ were noted with the HiPro formula. No significant relationships were detected between total essential or total nonessential amino acid concentrations and weight gain.

\section{DISCUSSION}

Protein accretion as determined by nitrogen balance was greater with the HiPro formula. Weight gain was also greater with the HiPro formula. None of the infants developed uremia or metabolic acidosis, and no differences were detected in acid-base status between the formulas. These data support the hypothesis that a formula with protein content of $3.6 \mathrm{~g} / 100$ kcal more closely meets requirements than a formula with a protein content of $3.0 \mathrm{~g} / 100 \mathrm{kcal}$. 

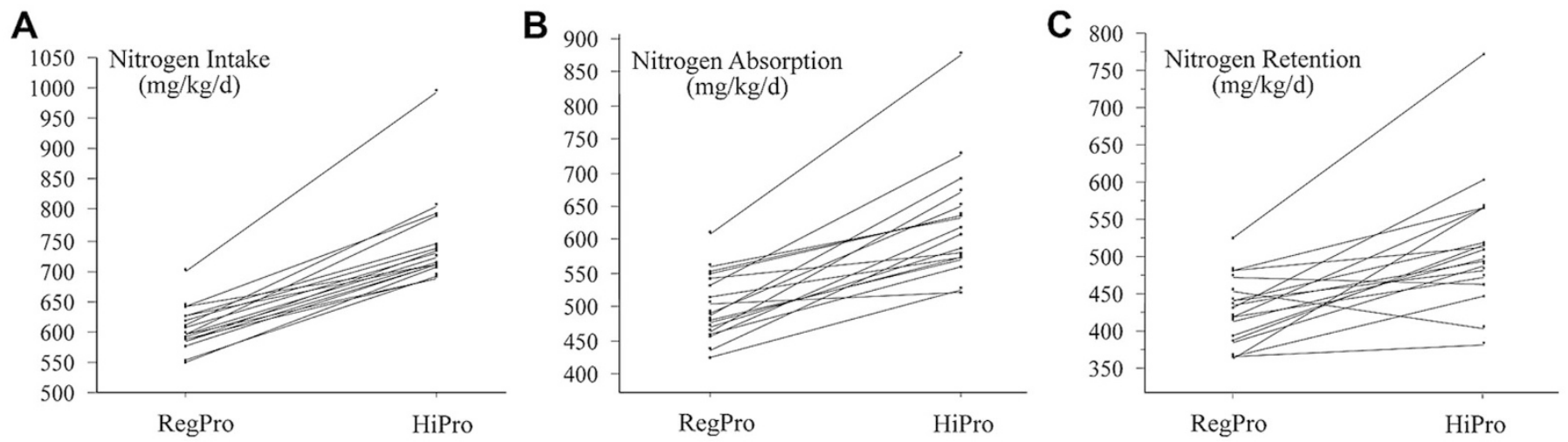

Figure 2. Nitrogen balance data for study infants ( $n=18$ infants, 36 balances). Intake $(A)$, absorption $(B)$ and retention $(C)$ were less with the RegPro than the HiPro formula ( $p<0.001$ for all comparisons).

Table 5. Nutrient balance results (mean $\pm 1 S D)$

\begin{tabular}{|c|c|c|c|c|c|c|}
\hline & & Intake & Absorption & $\%$ Absorption & Retention & $\%$ Retention \\
\hline Nitrogen & RegPro & $604 \pm 35$ & $500 \pm 49$ & $83 \pm 6$ & $426 \pm 45$ & $70 \pm 6$ \\
\hline (mg/kg/d) & HiPro & $743 \pm 71^{*}$ & $624 \pm 84^{*}$ & $84 \pm 6$ & $514 \pm 85^{*}$ & $71 \pm 6$ \\
\hline Fat & RegPro & $6.6 \pm 0.4$ & $4.8 \pm 0.7$ & $73 \pm 11$ & & \\
\hline Calcium & RegPro & $181 \pm 12$ & $82 \pm 36$ & $45 \pm 19$ & $81 \pm 35$ & $45 \pm 19$ \\
\hline$(\mathrm{mg} / \mathrm{kg} / \mathrm{d})$ & HiPro & $185 \pm 24$ & $85 \pm 32$ & $46 \pm 14$ & $83 \pm 32$ & $45 \pm 14$ \\
\hline Phosphorus & RegPro & $103 \pm 6$ & $90.9 \pm 7.1$ & $88.5 \pm 4.2$ & $66 \pm 11$ & $64 \pm 10$ \\
\hline$(\mathrm{mg} / \mathrm{kg} / \mathrm{d})$ & HiPro & $12.6 \pm 1.7^{*}$ & $6.0 \pm 2.2$ & $48 \pm 13$ & $5.6 \pm 2.1$ & $43 \pm 12$ \\
\hline Zinc & RegPro & $1964 \pm 137$ & $563 \pm 361$ & $28 \pm 18$ & $545 \pm 362$ & $27 \pm 18$ \\
\hline$(\mu \mathrm{g} / \mathrm{kg} / \mathrm{d})$ & HiPro & $1863 \pm 245^{*}$ & $561 \pm 355$ & $29 \pm 15$ & $538 \pm 354$ & $28 \pm 15$ \\
\hline Copper & RegPro & $205 \pm 18$ & $83 \pm 41$ & $40 \pm 19$ & & \\
\hline$(\mu \mathrm{g} / \mathrm{kg} / \mathrm{d})$ & HiPro & $170 \pm 22^{*}$ & $43 \pm 50 *$ & $25 \pm 29 *$ & & \\
\hline
\end{tabular}

* Differences significant at $p<0.001$

** Differences significant at $p<0.05$

Estimates of protein requirements are based on needs for maintenance and normal growth. However, it also takes time to establish adequate protein intakes in the VLBWI $(1,2,16)$. In one study, infants had accrued a net protein deficit of $18 \mathrm{~g} / \mathrm{kg}$ by $2 \mathrm{w}$ of age; i.e., summed difference between recommended and achieved intake for the $2 \mathrm{w}$ period (2). To recover this deficit before hospital discharge at $\sim 7 \mathrm{w}$ of age, recommended daily protein intake would need to have been increased by $0.5 \mathrm{~g} / \mathrm{kg} / \mathrm{d}$. In the present study, the deficit was $10 \mathrm{~g} / \mathrm{kg}$. To recoup this before hospital discharge, recommended protein intake would need to have increased by $0.4 \mathrm{~g} / \mathrm{kg}$.

At the average protein intake of $4.6 \mathrm{~g} / \mathrm{kg} / \mathrm{d}$, the protein accretion based on nitrogen retention was $3.2 \mathrm{~g} / \mathrm{kg} / \mathrm{d}$. Assuming that requirements for normal growth are $2.5 \mathrm{~g} / \mathrm{kg} / \mathrm{d}$ (3) then $0.7 \mathrm{~g} / \mathrm{kg} / \mathrm{d}$ was available for "catch-up." Because of a tendency to overestimate intake and underestimate losses during the balance procedure (17-19) $0.7 \mathrm{~g}$ is probably an overestimate. Nonetheless, it was paralleled by a growth rate $(35 \mathrm{~g} / \mathrm{d})$ which exceeded that in utero (25-30 g/d), suggesting that intake was meeting needs for 'catch-up' as well as normal growth. The lack of evidence of metabolic stress also supports the idea that the extra intake of protein provided by formula HiPro was used for growth.

Increased weight gain was noted in both sexes fed the HiPro formula. However, gain tended to be greater in boys than girls (mean difference $=10 \mathrm{~g} / \mathrm{d}$ ). This also is not surprising. Fetal
Table 6. Plasma amino acid concentrations (mean $\pm 1 S D$, $\mu m o l / d l)$ in the study infants compared to cord reference standard (15)

\begin{tabular}{lccc}
\hline Amino Acid & RegPro & HiPro & Reference \\
\hline Total essential & $107 \pm 20$ & $124 \pm 22^{*}$ & 149 \\
Lysine & $24 \pm 5$ & $30 \pm 6^{* *}$ & $41 \pm 5$ \\
Valine & $8.3 \pm 2.5$ & $10 \pm 2.6^{* *}$ & $26 \pm 5$ \\
Phenyalanine & $3.8 \pm 1.0$ & $4.1 \pm 1.1$ & $11 \pm 1.8$ \\
Methionine & $2.9 \pm .6$ & $2.9 \pm .6$ & $4.1 \pm 1.0$ \\
Tryptophan & $4.3 \pm 1.1$ & $4.5 \pm 1.0$ & - \\
Threonine & $33 \pm 12$ & $37 \pm 12$ & $29 \pm 5.3$ \\
Histidine & $8.1 \pm 1.6$ & $8.7 \pm 1.6$ & $11 \pm 1.8$ \\
Leucine & $8.9 \pm 3.3$ & $11 \pm 2.7$ & $13 \pm 2.2$ \\
Isoleucine & $4.7 \pm 1.5$ & $5.6 \pm 1.5$ & $7.6 \pm 1.9$ \\
Total non-essential & $168 \pm 22$ & $187 \pm 36^{* *}$ & 329 \\
Alanine & $23 \pm 5.2$ & $25 \pm 7.2$ & $68 \pm 16$ \\
Arginine & $9.3 \pm 3.3$ & $10 \pm 3.1$ & $5.7 \pm 6.0$ \\
Asparagine & $1.2 \pm 0.6$ & $1.1 \pm 0.6$ & $6.5 \pm 1.3$ \\
Asparagine & $5.5 \pm 1.4$ & $6.2 \pm 1.2^{*}$ & $5 \pm 1$ \\
Citrulline & $2.7 \pm .7$ & $3.0 \pm .6^{*}$ & $0.7 \pm 0.2$ \\
Cysteine & $0.9 \pm 1.3$ & $1.1 \pm 1.4$ & $0.1 \pm 0.2$ \\
Glutamate & $8.8 \pm 5.6$ & $11 \pm 9.1$ & $67 \pm 15$ \\
Glutamine & $47 \pm 19$ & $52 \pm 3.8^{*}$ & $28 \pm 20$ \\
Glycine & $18 \pm 3.8$ & $18 \pm 4.0$ & $49 \pm 13$ \\
Ornithine & $7.8 \pm 2.0$ & $10.3 \pm 2.0^{*}$ & $16 \pm 5.4$ \\
Proline & $15 \pm 2.2$ & $16 \pm 2.2^{*}$ & $22 \pm 3.7$ \\
Serine & $12 \pm 2.9$ & $15 \pm 1.7$ & $21 \pm 1.5$ \\
Taurine & $5.9 \pm 1.4$ & $6.5 \pm 2.5$ & $31 \pm 12$ \\
Tyrosine & $11.4 \pm 4$ & $14.6 \pm 1.2^{*}$ & $8.6 \pm 2.0$ \\
\hline Diference $b e c n$ & & &
\end{tabular}

* Differences between the study formulas significant at $p<0.05$

** Differences between the study formulas significant at $p<0.01$ 

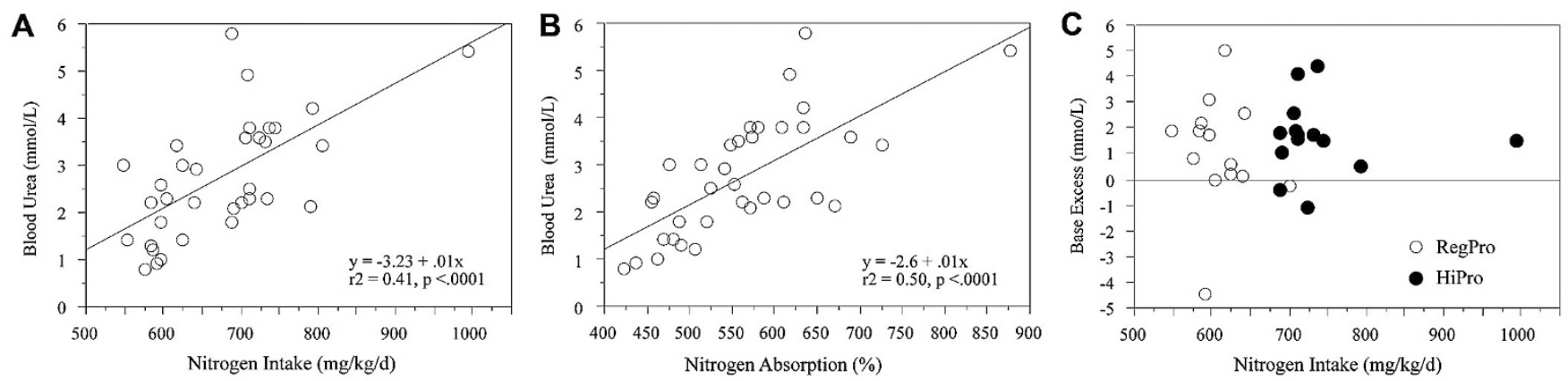

Figure 3. Relationship between serum chemistries and nitrogen balance ( $n=18$ infants, 36 balances). Blood urea (A and B), but not base excess (C), was linearly related to nitrogen intake and absorption $(p<0.0001)$.

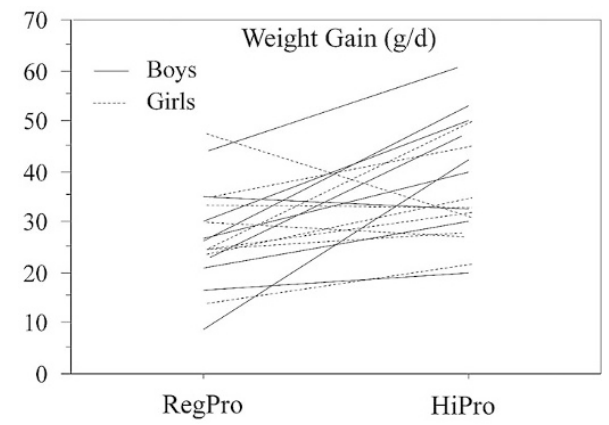

Figure 4. Weight gain in study infants $(n=9$ boys, $n=9$ girls). Weight gain $(\mathrm{g} / \mathrm{d})$ was less with the RegPro than the HiPro formula $(p<0.001)$.

growth rates are greater in boys than girls during the last trimester (20). Post-natally, pre-term infant boys grow faster and accrete more lean mass than pre-term girls (21). Pre-term boys fed a protein-enriched formula also grow faster and accrete more lean mass than girls fed the same formula (22). If boys are programmed to grow faster and intake better met requirements then gain would also tend to be greater.

In adults, urea production and blood urea levels increase with protein intake (23). Because of limited urea synthetic capacity (24-26), blood urea has not been considered a valid measure of protein intake in pre-term infants (27). In this study, urea increased linearly with protein intake and absorption, with variation in intake and absorption accounting for 42 and $50 \%$ of the variation in blood urea. At the same time, neither gestational age, post-natal age or postconceptional age had any significant effect on blood urea. These data indicate that blood urea is a valid measure of protein intake, an important consideration when fine-tuning intake to meet needs in this heterogeneous group of infants (28).

Pre-term infants fed mature human milk have lower PAA and grow more poorly than infants fed fortified human milk (29-34). In this study, infants fed the RegPro formula had lower PAA and grew more poorly than those fed the HiPro formula. A tenuous link appears to exist between lower protein intakes, lower PAA and poorer growth in the pre-term infant.

However, PAA in infants fed the HiPro formula were still less than cord reference values (15). Does this mean that protein intake was still inadequate? Perhaps, PAA may not be a valid measure of protein status in these infants? The answers are unclear. What is clear is that PAA profiles noted with the
HiPro formula were generally less than cord reference values, not associated with signs of metabolic stress or failure to thrive but better growth, suggesting that they are at least safe if not advantageous in these high-risk infants.

For all EAA, values were less than the cord reference. One exception was threonine, where values did not differ between the HiPro and RegPro formulas but were greater than the reference value (Table 5). This is not surprising with a whey hydrolysate formula. However, the differences were small and unlikely to be clinically relevant. For the NEAA, minor differences were noted between the two study formulas. Tyrosine values were greater with HiPro than the RegPro formula or the reference value. This also is not surprising because pre-term infants have limited capacity to degrade tyrosine (35). Yet, levels were still similar to our previous observations in the enterally-fed pre-term infant (4).

The findings of this study are important. It has been suggested that the nutrient value of a protein hydrolysate is not equivalent to the native protein in that it is associated with poorer protein absorption and retention and poorer growth than with the native whey proteins (36). In the present study, protein absorption and retention rates were at least similar and tended to be greater than our previously published values with unhydrolyzed whey predominant pre-term infant formulas (4).

Controversy exists about the protein-to-energy content of pre-term infant formulas. Micheli noted a linear relationship between intake and absorption when intake varied from 2-4 $\mathrm{g} / \mathrm{kg} / \mathrm{d}$ and suggested an upper limit of $4.0 \mathrm{~g} / \mathrm{kg} / \mathrm{d}$ or $3.3 \mathrm{~g} / 100$ kcal (37). Based upon a series of elegant studies in which protein:energy ratios were systematically varied, Kashyap, Heird et al. suggested an upper limit of $4.5 \mathrm{~g} / \mathrm{kg} / \mathrm{d}$ or 3.75 $\mathrm{g} / 100 \mathrm{kcal}$ (38). More recently, the same group were unable to demonstrate any advantage in lean mass accretion in infants 2.6 or $3.2 \mathrm{~g} / 100$ (39). In this parallel study, the sample size was small $(n=8, n=7 / \mathrm{gp})$ and negative findings are somewhat difficult to interpret.

In a comprehensive review, an Expert Panel recently recommended an upper limit of $4.5 \mathrm{~g} / \mathrm{kg} / \mathrm{d}$ or $3.6 \mathrm{~g} / 100 \mathrm{kcal}$ (27). In the present study, a linear relationship was noted between intake and absorption/retention when intake varied from 3.4 to $5.2 \mathrm{~g} / \mathrm{kg} / \mathrm{d}$ with no infants developing uremia or metabolic acidosis. These data are the first to suggest that a protein to energy ratio of $3.6 \mathrm{~g} / 100 \mathrm{kcal}$ is not only well tolerated but 
may, in some instances, more closely meets requirements in these rapidly growing and nutritionally-deprived infants.

Nonetheless, our findings have important limitations. The sample size was small. Extrapolation to a larger patient population is, therefore, difficult. The duration of intervention, one week, was also short. It is unclear how long-term feeding of the HiPro formula may affect metabolic status and growth in these high-risk infants. It is equally unclear how long such a formula should be fed. A longer term randomised controlledtrial is therefore needed to address these issues.

Acknowledgments. The authors would like to thank the medical and nursing staff of the Special Care Baby Unit at the Royal Victoria Infirmary in Newcastle-upon-Tyne for their support in this study. The authors would also like to thank Drs Marc Enslen and Corinne Hager, Nestec Ltd, Vevey, Switzerland for statistical expertise in analyzing the data.

\section{REFERENCES}

1. Carlson SJ, Ziegler EE 1998 Nutrient intakes and growth of very low birth weight infants. J Perinatol 18:252-258

2. Embleton NE, Pang N, Cooke RJ 2001 Postnatal malnutrition and growth retardation: an inevitable consequence of current recommendations in pre-term infants? Pediatrics 107:270-273

3. Ziegler EE, Thureen PJ, Carlson SJ 2002 Aggressive nutrition of the very low birthweight infant. Clin Perinatol 29:225-244

4. Cooke RJ, Watson D, Werkman S, Conner C 1992 Effects of type of dietary protein on acid-base status, protein nutritional status, plasma levels of amino acids, and nutrient balance in the very low birth weight infant. J Pediatr 121:444-451

5. Mihatsch WA, Franz AR, Hogel J, Pohlandt F 2002 Hydrolyzed protein accelerates feeding advancement in very low birth weight infants. Pediatrics 110:1199-1203

6. Cooke RJ, Perrin F, Moore J, Paule C, Ruckman K 1988 Methodology of nutrient balance studies in the pre-term infant. J Pediatr Gastroenterol Nutr 7:434-440

7. Nelson SE, Rogers RR, Frantz JA, Ziegler EE 1996 Palm olein in infant formula: absorption of fat and minerals by normal infants. Am J Clin Nutr 64:291-296

8. Conway EJ 1950 Microdiffusion Analysis and Volumetric Error. Crosby Lockwood \& Son, London, pp 1-164.

9. Leloir LF, Caardini CE 1957 Characterisation of phosphorus compounds by acid labillity. In: Colowick SP, Kaplan NO (eds) Methods in Enzymology Academic Press, New York, pp 840-850.

10. Van de Kamer JH, Ten Bokkel Huinink, H, Weijers H 1949 Rapid method of detemining fat in feces. J Biol Chem 177:347-

11. Kreutzer HJ 1976 An immunological turbidimetric method for serum transferrin determination. J Clin Chem Clin Biochem 14:401-406

12. Gulamali F, Keegan TE, Numerof B, Chrenka B, Wirth F, Pleban PA 1985 Kinetic nephelometric determination of transthyretin and retinol-binding protein in neonatal serum. Clin Chim Acta 147:197-204

13. Bachmann C Haschke-Becher E 2002 Plasma amino concentrations in breast and formula fed infants and references. In: Raiha NC, Rubaltelli FF (eds) Infant Formula: Closer to the Reference Lippincott Williams and Wilkins, Philadelphia, pp 121-135.

14. Schwartz GJ, Haycock GB, Edelmann CM, Spitzer A 1979 Late metabolic acidosis: a reassessment of the definition. J Pediatr 95:102-107

15. Pittard WB 3rd, Geddes KM, Picone TA 1988 Cord blood amino acid concentrations from neonates of 23-41 weeks gestational age. J Parenter Enteral Nutr 12:167-169
16. Cooke RJ, Ford A, Werkman S, Conner C, Watson D 1993 Postnatal growth in infants born between 700 and 1,500 g. J Pediatr Gastroenterol Nutr 16:130-135

17. Fomon SJ, Owen GM 1962 Comment on metabolic balance studies as a method of estimating body composition of infants. Pediatrics 29:495-498

18. Isaksson B, Sjogren B 1967 A critical evaluation of the calcium balance technic. I Variation in fecal output. Metabolism 16:295-302

19. Heroux O, Peter D 1975 Failure of balance measurements to predict actual retention of magnesium and calcium by rats as determined by direct carcass analysis. J Nutr 105:1157-1167

20. Kramer MS, Platt RW, Wen SW, Joseph KS, Allen A, Abrahamowicz M, Blondel B, Breart G Fetal/Infant Health Study Group of the Canadian Perinatal Surveillance System 2001 A new and improved population-based Canadian reference for birth weight for gestational age. Pediatrics 108:E35.

21. Cooke RJ, Rawlings DJ, McCormick K, Griffin IJ, Faulkner K, Wells JC, Smith JS, Robinson SJ 1999 Body composition of pre-term infants during infancy. Arch Dis Child Fetal Neonatal Ed 80:F188-F191

22. Cooke RJ, McCormick K, Griffin IJ, Embleton N, Faulkner K, Wells JC, Rawlings DC 1999 Feeding pre-term infants after hospital discharge: effect of diet on body composition. Pediatr Res 46:461-464

23. Morris SM Jr 1992 Regulation of enzymes of urea and arginine synthesis. Annu Rey Nutr 12:81-101.

24. Boehm G, Gedlu E, Muller MD, Beyreiss K, Raiha NC 1991 Postnatal development of urea- and ammonia-excretion in urine of very-low-birth-weight infants small for gestational age. Acta Paediatr Hung 31:31-45

25. Boehm G, Raiha NC 1993 Postmenstrual age correlates to indices of protein metabolism in very low birth weight infants. J Pediatr Gastroenterol Nutr 16:306310

26. Boehm G, Muller DM, Beyreiss K, Raiha NC 1988 Evidence for functional immaturity of the ornithine-urea cycle in very- low-birth-weight infants. Biol Neonate 54:121-125

27. Klein CJ 2002 Nutrient requirements for pre-term infant formulas. J Nutr 132:1395S-1577S.

28. Moro GE, Minoli I, Ostrom M, Jacobs JR, Picone TA, Raiha NC, Ziegler EE 1995 Fortification of human milk: evaluation of a novel fortification scheme and of a new fortifier. J Pediatr Gastroenterol Nutr 20:162-172

29. Davies DP 1977 Adequacy of expressed breast milk for early growth of pre-term infants. Arch Dis Child 52:296-301

30. Atkinson SA, Bryan MH, Anderson GH 1981 Human milk feeding in premature infants: protein, fat, and carbohydrate balances in the first two weeks of life. J of Pediatr 99:617-624

31. Gross SJ 1983 Growth and biochemical response of pre-term infants fed human milk or modified infant formula. N Engl J Med 308:237-241

32. Tyson JE, Lasky RE, Mize CE, Richards CJ, Blair-Smith N, Whyte R, Beer AE 1983 Growth, metabolic response, and development in very-low-birth-weight infants fed banked human milk or enriched formula. I. Neonatal findings. J Pediatr 103:95-104

33. Lucas A, Gore SM, Cole TJ, Bamford MF, Dossetor JF, Barr I, Dicarlo L, Cork S, Lucas PJ 1984 Multicentre trial on feeding low birthweight infants: effects of diet on early growth. Arch Dis Child 59:722-730

34. Putet G, Senterre J, Rigo J, Salle B 1984 Nutrient balance, energy utilization, and composition of weight gain in very-low-birth-weight infants fed pooled human milk or a pre-term formula. J Pediatr 105:79-85

35. Scriver CR, Rosenberg LE 1973 Tyrosine. In: Scriver CR, Rosenberg LE (eds) Amino Acid Metabolism and Its Disorders. Saunders, Philadelphia, pp 338-348.

36. Rigo J, Salle BL, Picaud JC, Putet G, Senterre J 1995 Nutritional evaluation of protein hydrolysate formulas. Eur J Clin Nutr 49:S26-38

37. Micheli J, Schutz Y 1993 Protein. In: Tsang R, Lucas A, Uauy R, Zlotkin S (eds) Nutritional needs of the pre-term infant: Scientific basis and practical guidelines Williams and Wilkins, Baltimore, pp 29-46

38. KashyapS, Heird WC 1994 Protein requirements of low birthweight, very low birthweight, and small for gestational age infants. In: Raiha N (ed) Protein Metabolism During Infancy Raven Press, New York, pp 133-151.

39. Fairey AK, Butte NF, Mehta N, Thotathuchery M, Schanler RJ, Heird WC 1997 Nutrient accretion in pre-term infants fed formula with different protein:energy ratios. J Pediatr Gastroenterol Nutr 25:37-45 